\title{
Time in Therapeutic Range and Disease Outcomes in Elderly Japanese Patients With Nonvalvular Atrial Fibrillation
}

\author{
Hiroshi Inoue, MD; Eitaro Kodani, MD; Hirotsugu Atarashi, MD; \\ Ken Okumura, MD; Takeshi Yamashita, MD; Yuji Okuyama, MD; \\ Hideki Origasa, $\mathrm{PhD}$ for the J-RHYTHM Registry Investigators
}

\begin{abstract}
Background: The relationship between warfarin treatment quality and prognosis for Japanese patients with nonvalvular atrial fibrillation (NVAF) has not been studied thoroughly.

Methods and Results: Data from the J-RHYTHM Registry were used to determine the time in therapeutic range (TTR) of the international normalized ratio (INR) of prothrombin time in elderly patients ( $\geq 70$ years). Target INR was 1.6-2.6. Of 7,406 patients with NVAF in the database, 3,832 elderly patients (mean $[ \pm S D]$ age $77.0 \pm 5.0$ years) constituted the study group. Of these patients, 459 did not receive warfarin and 3,373 received warfarin. Patients on warfarin were subdivided into 4 TTR groups: $<40 \%, 40-59.9 \%$, $60-79.9 \%$, and $\geq 80 \%$. During the 2-year follow-up, the incidence of thromboembolism and all-cause death was lower in patients with higher TTR (Ptrend<0.001); however, the incidence of major hemorrhage was higher in patients with TTR $<40 \%$. In multivariate analysis, compared with the no-warfarin group, TTR $60-79.9 \%$ and $\geq 80 \%$ were associated with lower thromboembolic risk, with hazard ratios $(\mathrm{HR})$ of 0.34 (95\% confidence interval $[\mathrm{Cl}] 0.17-0.67 ; \mathrm{P}=0.002)$ and $0.35(95 \% \mathrm{Cl} 0.18-0.68$; $\mathrm{P}=0.002)$, respectively, and lower all-cause death (HR 0.37 [95\% $\mathrm{Cl} 0.22-0.65 ; \mathrm{P}<0.001]$ and 0.43 [95\% $\mathrm{Cl} 0.26-0.71 ; \mathrm{P}=0.001]$, respectively). TTR <40\% was associated with major hemorrhage (HR 5.57; 95\% Cl 2.04-15.25; $\mathrm{P}=0.001$ ).
\end{abstract}

Conclusions: In elderly Japanese patients with NVAF, TTR should be maintained $\geq 60 \%$ to prevent thromboembolism and all-cause death. TTR $<40 \%$ should be avoided to prevent major hemorrhage.

Key Words: Atrial fibrillation; Elderly patients; Outcomes; Warfarin control

$\mathbf{O}$ ral anticoagulation therapy with warfarin is effective at reducing thromboembolic events in patients with atrial fibrillation (AF). Although the proportion of nonvalvular AF (NVAF) patients taking warfarin has been decreasing worldwide after the introduction of direct oral anticoagulants (DOAC) in clinical practice, warfarin is still prescribed in a substantial number of patients. ${ }^{1-3}$ A switch from warfarin to a DOAC may not be necessarily recommended in patients who are stable on warfarin. ${ }^{4}$ However, a major limitation of warfarin is its narrow therapeutic range (i.e., international normalized ratio [INR] of prothrombin time of 2.0-3.0 in Western countries $^{5,6}$ and of 1.6-2.6 for elderly patients in Japan ${ }^{7}$ ). Moreover, the quality of anticoagulation with warfarin is critical for the prevention of thromboembolic events without increasing hemorrhagic events. Time in therapeutic range (TTR) is an index used to assess the quality of warfarin treatment, ${ }^{8}$ and it has been reported that TTR should be maintained $>60 \%$ to prevent thromboembolism in patients with NVAF. ${ }^{-14}$ Morgan et al clearly showed that patients with NVAF and lower TTR (i.e., $<30 \%$ or $\leq 40 \%$ ) manifested with poor outcomes compared with patients receiving no warfarin. ${ }^{14}$ In Japan, this kind of analysis is still limited. ${ }^{11,15}$ Therefore, in the present study we analyzed the association between TTR and disease outcomes to determine a critical TTR for effective prevention of thromboembolic events without increasing hemorrhagic events in elderly patients with NVAF using the J-RHYTHM Registry dataset. ${ }^{16,17}$ Patients aged $<70$ years were excluded from the present subanalysis, because approximately $60 \%$ of these patients had baseline INR values lower than those recommended by the Japanese guidelines, ${ }^{7}$ thereby resulting in unpredictably lower TTR in patients aged $<70$ years. ${ }^{16}$

Received May 16, 2018; revised manuscript received June 28, 2018; accepted July 17, 2018; released online August 28 , 2018 Time for primary review: 27 days

Saiseikai Toyama Hospital, Toyama (H.I.); Department of Internal Medicine and Cardiology, Nippon Medical School Tama-Nagayama Hospital, Tokyo (E.K., H.A.); Department of Cardiology, Saiseikai Kumamoto Hospital, Kumamoto (K.O.); The Cardiovascular Institute, Tokyo (T.Y.); Okuyama Clinic, Osaka (Y.O.); and Division of Biostatistics and Clinical Epidemiology, University of Toyama, Graduate School of Medicine, Toyama (H.O.), Japan

Mailing address: Hiroshi Inoue, MD, Saiseikai Toyama Hospital, 33-1 Kusunoki, Toyama 931-8533, Japan. E-mail: h-inoue@ saiseikai-toyama.jp

ISSN-1346-9843 All rights are reserved to the Japanese Circulation Society. For permissions, please e-mail: cj@j-circ.or.jp 


\begin{tabular}{|c|c|c|c|c|c|c|}
\hline & \multirow{2}{*}{$\begin{array}{c}\text { No-warfarin } \\
\text { group } \\
(n=459)\end{array}$} & \multicolumn{4}{|c|}{ TTR (\%) } & \multirow[b]{2}{*}{$P_{\text {trend }}$} \\
\hline & & $\begin{array}{c}<40 \\
(n=342)\end{array}$ & $\begin{array}{l}40-59.9 \\
(n=485)\end{array}$ & $\begin{array}{c}60-79.9 \\
(n=1,008)\end{array}$ & $\begin{array}{c}\geq 80 \\
(n=1,538)\end{array}$ & \\
\hline Age (years) & $78.0 \pm 5.7$ & $78.2 \pm 5.0$ & $77.2 \pm 5.0$ & $76.7 \pm 4.9$ & $76.6 \pm 4.7$ & $<0.001$ \\
\hline Sex (female) & $173(37.7)$ & $125(36.5)$ & $156(32.2)$ & $382(37.9)$ & $532(34.6)$ & 0.417 \\
\hline BMI $\left(\mathrm{kg} / \mathrm{m}^{2}\right)$ & $23.1 \pm 3.4$ & $22.4 \pm 3.6$ & $23.1 \pm 7.2$ & $23.0 \pm 3.5$ & $23.3 \pm 3.2$ & 0.001 \\
\hline Type of AF & & & & & & $<0.001$ \\
\hline Paroxysmal & $254(55.3)$ & $117(34.2)$ & $140(28.9)$ & 341 (33.8) & $485(31.5)$ & \\
\hline Persistent & $39(8.5)$ & $50(14.6)$ & $73(15.1)$ & $141(14.0)$ & 207 (13.5) & \\
\hline Permanent & $166(36.2)$ & $175(51.2)$ & $272(56.1)$ & $526(52.2)$ & $846(55.0)$ & \\
\hline \multicolumn{7}{|l|}{ Comorbidities } \\
\hline Coronary artery disease & $64(13.9)$ & $43(12.6)$ & $74(15.3)$ & $140(13.9)$ & $179(11.6)$ & 0.148 \\
\hline Cardiomyopathy & $21(4.6)$ & $23(6.7)$ & $32(6.6)$ & $87(8.6)$ & $94(6.1)$ & 0.334 \\
\hline Hypertrophic & $8(1.7)$ & $13(3.8)$ & $9(1.9)$ & $47(4.7)$ & $47(3.1)$ & 0.171 \\
\hline Dilated & $13(2.8)$ & $10(2.9)$ & $23(4.7)$ & $40(4.0)$ & $47(3.1)$ & 0.999 \\
\hline COPD & $12(2.6)$ & $14(4.1)$ & $10(2.1)$ & $21(2.1)$ & $33(2.1)$ & 0.179 \\
\hline Hyperthyroidism & $5(1.1)$ & $2(0.6)$ & $3(0.6)$ & $19(1.9)$ & $20(1.3)$ & 0.255 \\
\hline \multicolumn{7}{|l|}{ Risk factors for stroke } \\
\hline Heart failure & $103(22.4)$ & $154(45.0)$ & $164(33.8)$ & $331(32.8)$ & $442(28.7)$ & 0.528 \\
\hline Hypertension & $287(62.5)$ & $208(60.8)$ & $326(67.2)$ & $674(66.9)$ & $1,012(65.8)$ & 0.091 \\
\hline Age $\geq 75$ years & $308(67.1)$ & $247(72.2)$ & $318(65.6)$ & $616(61.1)$ & $942(61.2)$ & $<0.001$ \\
\hline Diabetes mellitus & 75 (16.3) & $73(21.3)$ & $110(22.7)$ & $174(17.3)$ & $309(20.1)$ & 0.496 \\
\hline Stroke/TIA & $54(11.8)$ & $60(17.5)$ & $74(15.3)$ & $179(17.8)$ & $245(15.9)$ & 0.109 \\
\hline $\mathrm{CHADS}_{2}$ score & $1.9 \pm 1.2$ & $2.3 \pm 1.2$ & $2.2 \pm 1.2$ & $2.1 \pm 1.2$ & $2.1 \pm 1.2$ & 0.423 \\
\hline $\mathrm{CHA}_{2} \mathrm{DS}_{2}$-VASc score & $3.4 \pm 1.4$ & $3.8 \pm 1.3$ & $3.7 \pm 1.3$ & $3.7 \pm 1.4$ & $3.5 \pm 1.4$ & 0.160 \\
\hline HAS-BLED score & $2.1 \pm 0.8$ & $2.0 \pm 0.9$ & $2.0 \pm 0.9$ & $1.9 \pm 0.9$ & $1.7 \pm 0.8$ & $<0.001$ \\
\hline Warfarin dose (mg/day) & - & $2.3 \pm 1.1$ & $2.5 \pm 1.0$ & $2.6 \pm 1.1$ & $2.7 \pm 1.0$ & $<0.001$ \\
\hline INR & - & $1.71 \pm 0.65$ & $1.84 \pm 0.55$ & $1.93 \pm 0.52$ & $1.95 \pm 0.38$ & $<0.001$ \\
\hline No. INR determinations & - & $10.8 \pm 5.8$ & $13.6 \pm 5.2$ & $14.7 \pm 5.1$ & $14.1 \pm 5.5$ & $<0.001$ \\
\hline $\operatorname{TTR}^{\mathrm{A}}(\%)$ & - & $21.9 \pm 13.4$ & $51.8 \pm 5.6$ & $71.1 \pm 5.6$ & $91.4 \pm 6.3$ & $<0.001$ \\
\hline TSupraTR (\%) & & $13.1 \pm 25.1$ & $13.6 \pm 15.8$ & $11.0 \pm 10.4$ & $3.5 \pm 4.8$ & $<0.001$ \\
\hline TSubTR (\%) & & $65.0 \pm 29.5$ & $34.5 \pm 16.8$ & $17.9 \pm 11.2$ & $5.0 \pm 5.6$ & $<0.001$ \\
\hline Antiplatelet drugs & 295 (64.3) & $100(29.2)$ & 145 (29.9) & $245(24.3)$ & 337 (21.9) & $<0.001$ \\
\hline Aspirin & 252 (54.9) & 75 (21.9) & $116(23.9)$ & $214(21.2)$ & $286(18.6)$ & $<0.001$ \\
\hline Others & 70 (15.3) & $33(9.6)$ & $48(9.9)$ & $57(5.7)$ & $79(5.1)$ & $<0.001$ \\
\hline
\end{tabular}

Data are given as the number of patients (\%) or as the mean \pm SD. AThe target INR of prothrombin time was 1.6-2.6. AF, atrial fibrillation; BMI, body mass index; COPD, chronic obstructive pulmonary disease; CHADS 2 , congestive heart failure, hypertension, age $\geq 75$ years, diabetes mellitus, and history of stroke or TIA; $\mathrm{CHA}_{2} \mathrm{DS}_{2}-\mathrm{VASc}, \mathrm{CHADS}_{2}$ components plus vascular disease (coronary artery disease), age 70-74 years in the present analysis, and female sex; HAS-BLED, hypertension (systolic blood pressure $\geq 140 \mathrm{mmHg}$ ), abnormal renal/liver function, stroke, bleeding history or predisposition, labile INR (episodes of INR $\geq 3.5$ ), elderly (age $>70$ years in the present analysis), drugs (use of antiplatelet drugs)/alcohol concomitantly; INR, international normalized ratio; TIA, transient ischemic attack; TTR, time in therapeutic range; TSupraTR, time in supratherapeutic range (INR >2.6); TSubTR, time in subtherapeutic range (INR <1.6).

\section{Methods}

\section{Study Protocol}

The J-RHYTHM Registry (UMIN Clinical Trials Registry UMIN000001569) is a prospective observational investigation that enrolled patients with AF from January to July 2009 after obtaining written informed consent. ${ }^{17}$ The study design and baseline characteristics of the patients have been reported elsewhere. ${ }^{16,17}$ Briefly, the study protocol conformed to the Declaration of Helsinki and was approved by the ethics committee of each participating institution. A consecutive series of outpatients with AF of any type was enrolled. Patients who presented with mitral stenosis, underwent mechanical valve replacement, or missed the follow-up examinations were excluded from the present analysis. Antithrombotic drugs and dosages were selected at the discretion of treating physicians. Anticoagulation intensity was determined by assessing the INR values, at least bimonthly. ${ }^{17}$ The TTR was determined as an index of the quality of warfarin treatment by using the method developed by Rosendaal et al. ${ }^{8}$ For determination of TTR, the target INR level was set at 1.6-2.6 for elderly patients aged $\geq 70$ years based on a previous study by Yasaka et al ${ }^{18}$ and the Japanese guidelines. ${ }^{7}$ The time in INR $>2.6$ or $<1.6$ was also determined. Patients were divided into 5 groups based on warfarin use and 4 TTR values (i.e., no-warfarin and TTR $<40 \%, 40-59.9 \%, 60-79.9 \%$, and $\geq 80 \%$ ).

\section{Endpoints}

Patients were followed-up for 2 years or until the occurrence of an adverse event, whichever occurred first. Primary endpoints were thromboembolism (including symptomatic 


\begin{tabular}{|c|c|c|c|c|c|c|}
\hline & \multirow{2}{*}{$\begin{array}{c}\text { No-warfarin } \\
\text { group } \\
(\mathrm{n}=459)\end{array}$} & \multicolumn{4}{|c|}{ TTR (\%) } & \multirow[b]{2}{*}{ Ptrend } \\
\hline & & $\begin{array}{c}<40 \\
(n=342)\end{array}$ & $\begin{array}{l}40-59.9 \\
(n=485)\end{array}$ & $\begin{array}{c}60-79.9 \\
(n=1,008)\end{array}$ & $\begin{array}{c}\geq 80 \\
(n=1,538)\end{array}$ & \\
\hline Thromboembolism & $19(4.1)$ & $18(5.3)$ & $13(2.7)$ & $13(1.3)$ & $28(1.8)$ & $<0.001$ \\
\hline Major hemorrhage & $5(1.1)$ & $19(5.6)$ & $8(1.6)$ & $23(2.3)$ & $39(2.5)$ & 0.836 \\
\hline All-cause death & $29(6.3)$ & $21(6.1)$ & $23(4.7)$ & 33 (3.3) & $38(2.5)$ & $<0.001$ \\
\hline Composite events ${ }^{A}$ & $53(11.5)$ & $58(17.0)$ & $44(9.1)$ & $69(6.8)$ & $105(6.8)$ & $<0.001$ \\
\hline
\end{tabular}

Data are given as number of patients (\%). ${ }^{A}$ Composite of thromboembolism, major hemorrhage, and all-cause death. TTR, time in therapeutic range.

\begin{tabular}{|lccccc|}
\hline \multicolumn{7}{|c|}{ Table 3. Receiver Operating Characteristic Curve Analysis } & & & \\
& $\begin{array}{c}\text { AUC } \\
(\mathbf{9 5 \%} \text { Cl) }\end{array}$ & P value & $\begin{array}{c}\text { Cut-off TTR } \\
\text { (\%) }\end{array}$ & $\begin{array}{c}\text { Sensitivity } \\
\text { (\%) }\end{array}$ & $\begin{array}{c}\text { Specificity } \\
\text { (\%) }\end{array}$ \\
Thromboembolism & $0.582(0.503-0.662)$ & 0.017 & 65.9 & 69.3 & 51.4 \\
Major hemorrhage & $0.525(0.455-0.596)$ & 0.414 & 51.1 & 84.0 & 27.0 \\
All-cause death & $0.574(0.514-0.634)$ & 0.007 & 66.4 & 68.8 & 50.4 \\
Composite events $^{\mathrm{A}}$ & $0.564(0.523-0.605)$ & $<0.001$ & 66.8 & 68.9 & 46.7 \\
\hline
\end{tabular}

${ }^{\mathrm{A} C o m p o s i t e}$ of thromboembolism, major hemorrhage, and all-cause death. ${ }^{\mathrm{B}}$ Values at maximum Youden's index (=sensitivity+specificity-1). AUC, area under the curve; Cl, confidence interval; TTR, time in therapeutic range.

\begin{tabular}{|c|c|c|c|c|}
\hline & \multirow{2}{*}{$\begin{array}{c}\text { No-warfarin } \\
\text { group } \\
(\mathrm{n}=459)\end{array}$} & \multicolumn{2}{|c|}{ TTR (\%) } & \multirow[b]{2}{*}{ Ptrend } \\
\hline & & $\begin{array}{c}<66 \\
(n=1,058)\end{array}$ & $\begin{array}{c}\geq 66 \\
(n=2,315)\end{array}$ & \\
\hline Thromboembolism & $19(4.1)$ & $37(3.5)$ & $35(1.5)$ & $<0.001$ \\
\hline Major hemorrhage & $5(1.1)$ & $32(3.0)$ & 57 (2.5) & 0.334 \\
\hline All-cause death & $29(6.3)$ & $55(5.2)$ & $60(2.6)$ & $<0.001$ \\
\hline Composite events ${ }^{A}$ & $53(11.5)$ & $124(11.7)$ & $152(6.6)$ & $<0.001$ \\
\hline
\end{tabular}

Data are given as number of patients (\%). ${ }^{A}$ Composite of thromboembolism, major hemorrhage, and all-cause death. TTR, time in therapeutic range.

ischemic stroke, transient ischemic attack [TIA], and systemic embolic events), major hemorrhagic events (including intracranial hemorrhage, gastrointestinal hemorrhage, and other hemorrhages requiring hospitalization), or allcause death. A composite endpoint of thromboembolism, major hemorrhage, and all-cause death was also evaluated. The diagnostic criteria for each event have been described elsewhere. ${ }^{17}$

\section{Statistical Analysis}

Data are presented as the mean \pm SD. The significance of differences in mean values was analyzed using analysis of variance (ANOVA). Frequencies of parameters or events were compared using the Chi-squared test or Fisher's exact test, as appropriate. Kaplan-Meier curves were used to compare the time of the events by applying log-rank tests. The cut-off values for TTR for predicting the disease outcomes were determined with the receiver operating characteristic (ROC) curve. Cox proportional hazards model was used to investigate the effects of TTR on the events. Hazard ratios (HRs) and 95\% confidence interval (CI) of the 4 TTR groups were calculated with the no-warfarin group as a reference. Explanatory variables used in multivariate analyses were well-known risk factors, namely components of the $\mathrm{CHA}_{2} \mathrm{DS}_{2}$-VASc score (congestive heart failure, hypertension, age $\geq 75$ years, diabetes mellitus, history of stroke or TIA, vascular disease [coronary artery disease in the present study], and female sex), ${ }^{19}$ antiplatelet drug use, and type of AF. Two-tailed $\mathrm{P}<0.05$ was considered significant. All statistical analyses were performed using SPSS version 23.0 (IBM Corp., Armonk, NY, USA).

\section{Results}

Of 7,937 patients with AF enrolled in the Registry, follow-up data were available for 7,406 patients with NVAF. ${ }^{20}$ Of these patients, TTR was available for 6,064 (2,691 patients aged $<70$ years and 3,373 patients aged $\geq 70$ years). Warfarin was not administered in 459 patients aged $\geq 70$ years. Therefore, 3,832 elderly patients (mean age $77.0 \pm 5.0$ years, $64.3 \%$ males) with TTR or without warfarin treatment constituted the study group.

\section{Patients' Clinical Characteristics}

The characteristics of the patients are given in Table $\mathbf{1}$. Although the prevalence rates of most of the comorbidities were comparable among the groups, patients belonging in the TTR $<40 \%$ group were older and had a lower body mass index. Thromboembolic (CHADS 2 and $\left.\mathrm{CHA}_{2} \mathrm{DS}_{2}-\mathrm{VASc}\right)$ risk scores ${ }^{19,21}$ did not differ among the 5 groups, but hemorrhagic risk (HAS-BLED) scores ${ }^{22}$ did. Daily doses of warfarin and baseline INR values were lower in the TTR 


\section{A Thromboembolism}

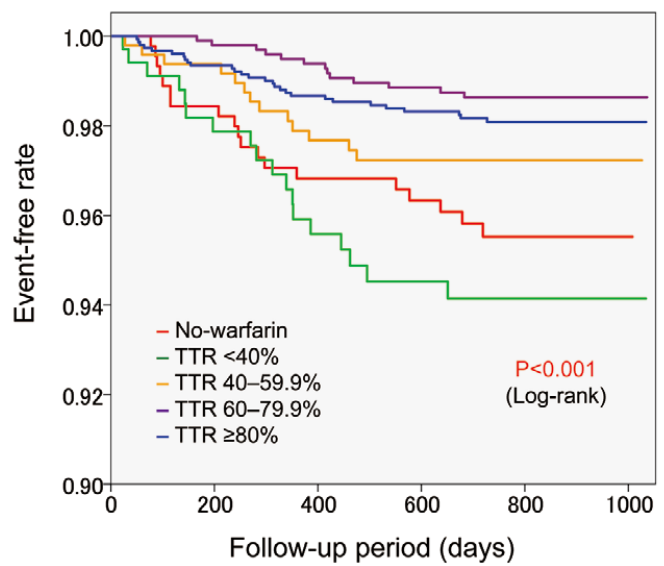

B Major hemorrhage

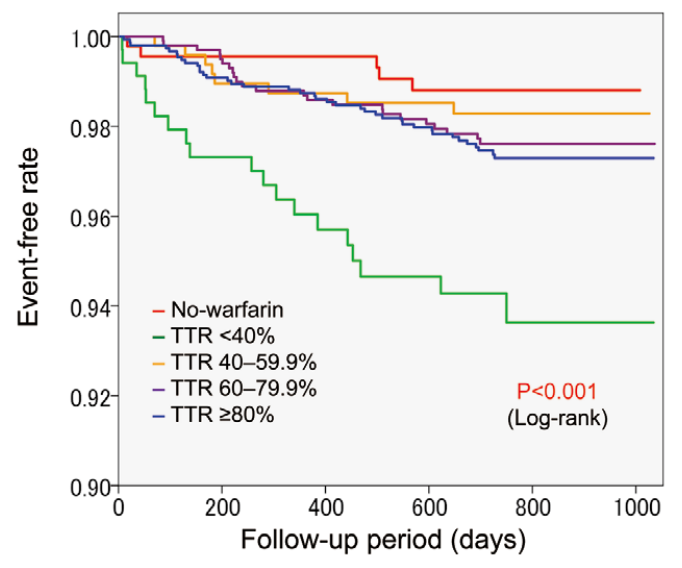

C All-cause death

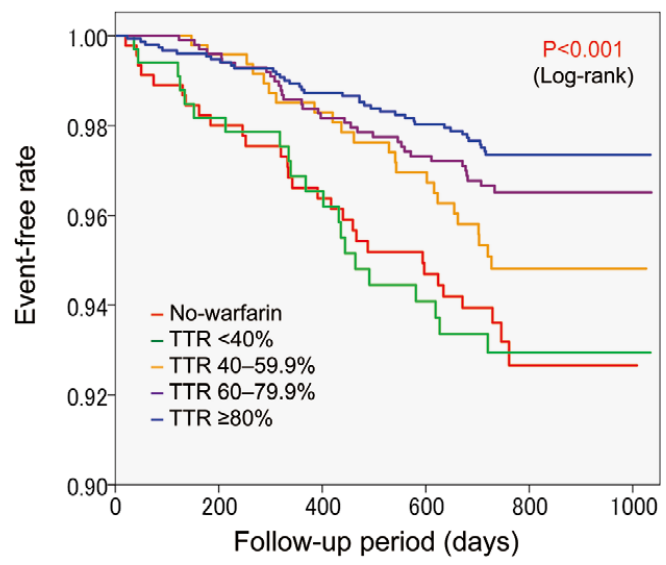

Figure 1. Kaplan-Meier curves for the incidence of $(\mathbf{A})$ thromboembolism, (B) major hemorrhage, and (C) all-cause death according to warfarin use and the 4 time in TTR strata. TTR, time in therapeutic range.

$<40 \%$ group. The mean TTR values differed significantly among the 4 TTR groups for the study design. The number of the INR determinations also differed significantly among the 4 TTR groups $\left(\mathrm{P}_{\text {trend }}<0.001\right)$, with the lowest number of determinations in the TTR $<40 \%$ group. Concomitant use of antiplatelet drugs was more frequent in the no-warfarin group.

\section{Event Rates}

During the 2-year follow-up period, 91 patients experienced thromboembolic events, 94 patients experienced major hemorrhagic events, and 144 patients died (Table 2). Incidence rates differed significantly for thromboembolism and all-cause death among the 5 groups, but not for major hemorrhages. Consequently, the rate of composite events differed among the 5 groups.

The cut-off values for TTR to predict disease outcomes are given in Table 3. When patients on warfarin were divided into 2 groups based on a TTR cut-off value of $66 \%$, the TTR $<66 \%$ group did not show any benefit for the prevention of thromboembolism and composite events compared with the no-warfarin group (Table 4; Figures S1,S2).

The Kaplan-Meier curves for the disease outcome were compared among the 5 groups (Figures 1,2). Notably, the event-free survival rates for thromboembolism, major hemorrhages, and composite events were lower in the TTR $<40 \%$ group than in the no-warfarin group.

In univariate analysis (Table 5), TTR $<40 \%$ was associated with a higher risk for major hemorrhages and composite events compared with the no-warfarin group. TTR $\geq 60 \%$ was associated with a lower risk of thromboembolism, all-cause death, and composite events. As expected, an increase in time in the supratherapeutic range (i.e., INR values $>2.6$ ) was associated with a higher risk of major hemorrhages (Table S1). In contrast, an increase in time in the subtherapeutic range (i.e., INR values <1.6) was associated with a higher risk of thromboembolism (Table S1). In multivariate analysis (Table 6), TTR $<40 \%$ and $\geq 60 \%$ was associated with outcome events, as in the univariate analysis. Several other comorbidities were associated with outcome events. 


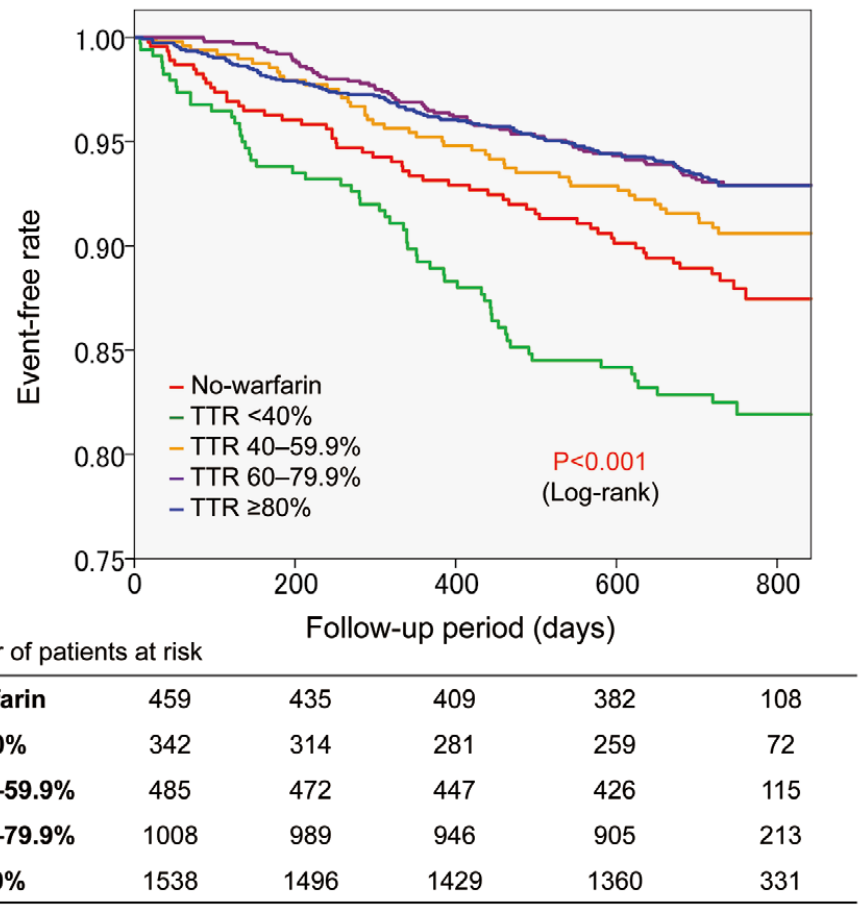

Figure 2. Kaplan-Meier curves for the incidence of the composite of thromboembolism, major hemorrhage, and all-cause death according to warfarin use and 4 TTR strata. TTR, time in therapeutic range.

\begin{tabular}{|c|c|c|c|c|c|c|c|c|}
\hline \multirow[b]{3}{*}{$\begin{array}{l}\text { No-warfarin } \\
\text { group }\end{array}$} & \multicolumn{2}{|c|}{ Thromboembolism } & \multicolumn{2}{|c|}{ Major hemorrhage } & \multicolumn{2}{|c|}{ All-cause death } & \multicolumn{2}{|c|}{ Composite events ${ }^{A}$} \\
\hline & HR (95\% Cl) & $P$ value & HR (95\% Cl) & $P$ value & HR (95\% Cl) & $P$ value & HR (95\% Cl) & $P$ value \\
\hline & Ref. & - & Ref. & - & Ref. & - & Ref. & - \\
\hline \multicolumn{9}{|l|}{ TTR (\%) } \\
\hline$<40$ & $1.34(0.69-2.60)$ & 0.392 & $6.06(2.26-16.23)$ & $<0.001$ & $1.06(0.59-1.89)$ & 0.851 & $1.63(1.12-2.38)$ & 0.011 \\
\hline $40-59.9$ & $0.58(0.30-1.11)$ & 0.098 & $1.41(0.49-4.07)$ & 0.521 & $0.68(0.41-1.13)$ & 0.139 & $0.71(0.49-1.03)$ & 0.074 \\
\hline $60-79.9$ & $0.36(0.19-0.70)$ & 0.002 & $1.95(0.75-5.12)$ & 0.174 & $0.39(0.23-0.65)$ & $<0.001$ & $0.53(0.37-0.76)$ & $<0.001$ \\
\hline$\geq 80$ & $0.39(0.21-0.73)$ & 0.003 & $2.38(0.93-6.07)$ & 0.070 & $0.43(0.26-0.70)$ & 0.001 & $0.60(0.43-0.84)$ & 0.003 \\
\hline
\end{tabular}

${ }^{A}$ Composite of thromboembolism, major hemorrhage, and all-cause death. $\mathrm{Cl}$, confidence interval; HR, hazard ratio; TTR, time in therapeutic range.

\section{Discussion}

We examined the relationship between the quality of warfarin treatment and the prognosis for elderly NVAF patients aged $\geq 70$ years in whom target INR values between 1.6 and 2.6 are recommended by the Japanese guidelines. ${ }^{7}$ The major findings of the present study were that TTR was independently associated with the disease outcomes compared with the no-warfarin group and that TTR $<40 \%$ was associated with a higher rate of major hemorrhage, but, in contrast, TTR $\geq 60 \%$ was associated with better prognosis in terms of thromboembolism, all-cause death, and composite events.

\section{TTR Values and Prognosis}

The intensity of anticoagulation with warfarin, measured in terms of INR values, is critical for the prevention of thromboembolic events among patients with NVAF receiving warfarin. According to guidelines in Europe, ${ }^{5}$
North America, ${ }^{6}$ and Japan, ${ }^{7}$ target INR values are in the range 2.0-3.0, except for elderly NVAF patients in Japan, for whom INR values in the range 1.6-2.6 are recommended.7,18 In addition to the INR value itself, it has been reported that the TTR (which is an index of the quality of INR control) needs to be maintained above $60-75 \%$ for a significant reduction in stroke and systemic embolism. ${ }^{-14}$

Masaki et al ${ }^{11}$ determined the relationship between TTR and the incidence of stroke in 188 elderly Japanese patients with AF. As in the present study, the target INR values in that study were set at 1.6-2.6. ROC curve analysis by Masaki et a ${ }^{11}$ revealed that the cut-off value for TTR was $68 \%$ to ensure anticoagulation benefit. The TTR $\leq 68 \%$ group did not show any benefit compared with the nowarfarin group. ${ }^{11}$ However, in that study the relationship between TTR and hemorrhagic events or mortality was not significant.

In a subanalysis of SPORTIF-III and IV, ${ }^{9}$ patients with NVAF on warfarin were divided into 3 groups considering 


\begin{tabular}{|c|c|c|c|c|c|c|c|c|}
\hline & \multicolumn{2}{|c|}{ Thromboembolism } & \multicolumn{2}{|c|}{ Major hemorrhage } & \multicolumn{2}{|c|}{ All-cause death } & \multicolumn{2}{|c|}{ Composite eventsc } \\
\hline & HR (95\% Cl) & $P$ value & HR (95\% Cl) & $P$ value & HR (95\% Cl) & $P$ value & HR (95\% Cl) & $P$ value \\
\hline \multicolumn{9}{|l|}{ TTR (\%) } \\
\hline$<40^{A}$ & $1.20(0.59-2.41)$ & 0.614 & $5.57(2.04-15.25)$ & 0.001 & $0.81(0.44-1.47)$ & 0.487 & $1.38(0.93-2.04)$ & 0.112 \\
\hline $40-59.9^{\mathrm{A}}$ & $0.51(0.25-1.01)$ & 0.054 & $1.35(0.46-3.97)$ & 0.583 & $0.60(0.35-1.01)$ & 0.053 & $0.65(0.44-0.96)$ & 0.028 \\
\hline $60-79.9^{\mathrm{A}}$ & $0.34(0.17-0.67)$ & 0.002 & $1.99(0.74-5.36)$ & 0.172 & $0.37(0.22-0.65)$ & $<0.001$ & $0.52(0.36-0.75)$ & 0.001 \\
\hline$\geq 80^{A}$ & $0.35(0.18-0.68)$ & 0.002 & $2.40(0.91-6.30)$ & 0.076 & $0.43(0.26-0.71)$ & 0.001 & $0.59(0.41-0.84)$ & 0.004 \\
\hline Heart failure & $0.79(0.50-1.26)$ & 0.325 & $1.39(0.91-2.14)$ & 0.129 & $2.79(1.97-3.94)$ & $<0.001$ & $1.63(1.30-2.05)$ & $<0.001$ \\
\hline Hypertension & $0.94(0.61-1.44)$ & 0.769 & $1.66(1.03-2.66)$ & 0.037 & $0.75(0.54-1.05)$ & 0.096 & $0.99(0.78-1.24)$ & 0.895 \\
\hline $\begin{array}{l}\text { Age } \geq 75 \\
\text { years }\end{array}$ & $1.74(1.07-2.83)$ & 0.025 & $1.66(1.04-2.65)$ & 0.035 & $3.26(2.03-5.25)$ & $<0.001$ & $2.18(1.66-2.86)$ & $<0.001$ \\
\hline $\begin{array}{l}\text { Diabetes } \\
\text { mellitus }\end{array}$ & $1.22(0.74-2.00)$ & 0.444 & $0.95(0.56-1.58)$ & 0.848 & $1.09(0.74-1.62)$ & 0.652 & $1.08(0.83-1.41)$ & 0.553 \\
\hline Stroke/TIA & $1.68(1.03-2.73)$ & 0.039 & $1.38(0.84-2.26)$ & 0.199 & $1.51(1.01-2.23)$ & 0.042 & $1.51(1.17-1.97)$ & 0.002 \\
\hline $\begin{array}{l}\text { Vascular } \\
\text { diseases }\end{array}$ & $0.92(0.48-1.75)$ & 0.797 & $1.11(0.61-2.00)$ & 0.739 & $2.19(1.47-3.26)$ & $<0.001$ & $1.50(1.12-2.00)$ & 0.006 \\
\hline Female sex & $0.85(0.55-1.34)$ & 0.488 & $0.57(0.35-0.91)$ & 0.020 & $0.62(0.42-0.90)$ & 0.012 & $0.66(0.52-0.85)$ & 0.001 \\
\hline $\begin{array}{l}\text { Persistent } \\
\mathrm{AF}^{\mathrm{B}}\end{array}$ & $1.28(0.60-2.74)$ & 0.525 & $1.22(0.63-2.36)$ & 0.560 & $0.89(0.49-1.63)$ & 0.705 & $1.08(0.74-1.59)$ & 0.697 \\
\hline $\begin{array}{l}\text { Permanent } \\
\mathrm{AF}^{\mathrm{B}}\end{array}$ & $2.00(1.20-3.35)$ & 0.008 & $1.21(0.74-1.98)$ & 0.444 & $1.21(0.82-1.80)$ & 0.336 & $1.39(1.07-1.80)$ & 0.015 \\
\hline $\begin{array}{l}\text { Antiplatelet } \\
\text { use }\end{array}$ & $1.05(0.65-1.71)$ & 0.833 & $1.26(0.78-2.03)$ & 0.341 & $1.21(0.83-1.77)$ & 0.315 & $1.18(0.92-1.52)$ & 0.192 \\
\hline
\end{tabular}

${ }^{A}$ Compared with no-warfarin. ${ }^{B}$ Compared with paroxysmal AF. ${ }^{C}$ Composite of thromboembolism, major hemorrhage, and all-cause death.

Vascular disease, coronary artery disease. Other abbreviations as in Tables 1,5.

the quality of INR control (i.e., poor, moderate, and good control based on TTR). The findings of that study indicated that TTR calculated with target INR values of $2-3$ should be maintained above $75 \%$ to prevent stroke and systemic embolism, and above $65 \%$ to decrease all-cause death and major hemorrhage. ${ }^{9}$ In a subanalysis of the RE-LY, patients belonging to the warfarin group were divided into groups based on 4 individual TTR, and TTR $\geq 67.2 \%$ was associated with lower rates for the events. ${ }^{23}$ However, in these studies a no-warfarin group was not included as a reference., 923

In a systematic review, Wan et $\mathrm{al}^{24}$ indicated that an $8.3 \%$ increase in TTR significantly reduced the incidence of major hemorrhage by 1 event per 100 patient-years, and a $10.2 \%$ increase in TTR reduced the incidence of thromboembolic events by 1 event per 100 patient-years among patients on warfarin. Wan et $\mathrm{al}^{24}$ recommended that anticoagulation processes aim for a TTR of $70-80 \%$ to optimize the benefits and reduce the harm in patients on warfarin. Morgan et a ${ }^{14}$ compared event rates of 6 TTR groups receiving warfarin with those of the no-warfarin group among patients with NVAF and found that, compared with the no-warfarin group, TTR $\geq 41 \%$ was associated with a lower incidences of all-cause death, and TTR $\geq 71 \%$ was associated with a lower incidence of stroke for patients with a CHADS 2 score $\geq 2$. When all patients were included in the analysis, TTR $\geq 41 \%$ was observed to be associated with a lower rate of stroke and TTR $\geq 31 \%$ was associated a with lower rate of all-cause death. ${ }^{14}$ In the present study, the critical TTR values for better prognosis differed slightly from those suggested by Morgan et al; ${ }^{14}$ specifically, TTR $\geq 60 \%$ (or $\geq 66 \%$ as determined by ROC curve analysis) was required for a lower incidence of thromboembolism and all-cause death compared with the no-warfarin group. The difference in the association of
TTR values with outcome events between the present study and the study of Morgan et a ${ }^{14}$ could be attributed, at least in part, to differences in the clinical characteristics of the patients enrolled in the studies. For example, Morgan et a ${ }^{14}$ included younger as well as elderly patients (vs. only elderly patients in the present study), who had been hospitalized in 1995-2000 (vs. outpatients in 2009 in the present study). In addition, patients in the study of Morgan et al14 had a lower prevalence of hypertension $(16.7 \%$; vs. $65.4 \%$ in the present study), a lower mean CHADS2 score (1.04; vs. 2.1 in the present study), and a higher rate of all-cause death $(237.7 / 1,000$ person/years for the no-warfarin group; vs. $6.3 \% / 2$ years in the present study).

TTR $<40 \%$ was associated with major hemorrhagic events in the present study. This association seemed difficult to explain, because the TTR $<40 \%$ group had a similar HAS-BLED score, as well as a similar time in the supratherapeutic range as the TTR $40-59.9 \%$ group. Some confounding factors not determined in the present analysis could have been involved in the association between TTR $<40 \%$ and major hemorrhagic events.

In the multivariate analysis, some clinical variables in addition to age emerged as independent predictors of disease outcomes. Hypertension is a component of the bleeding risk score (i.e., HAS-BLED); ${ }^{22}$ therefore, it was associated with the incidence of major hemorrhage. In the case of thromboembolism, a previous history of stroke/TIA events emerged as an independent predictor, as expected from the risk scores. ${ }^{9,21}$ It seems likely that vascular diseases (coronary artery disease in the present analysis) and heart failure were associated with the incidence of all-cause death. Female sex was observed to be associated with a lower risk of major hemorrhage and all-cause death, as reported in the previous sub-analysis of the J-RHYTHM Registry. ${ }^{25}$ Compared with paroxysmal AF, permanent 
AF emerged as an independent predictor of thromboembolism, a finding consistent with other studies. ${ }^{26,27}$ When the multivariate analysis was performed with different explanatory variables, permanent AF did not emerge as an independent predictor of thromboembolism, as reported in our previous subanalysis of the J-RHYTHM Registry. ${ }^{28}$ Therefore, the association of AF type with thromboembolic events should be interpreted with caution.

\section{Study Limitations}

The present subanalysis had several limitations. First, this subanalysis was a post hoc analysis of an observational study and was therefore hypothesis generating in nature. Second, younger patients ( $<70$ years) were not included in the present analysis. The Japanese guidelines ${ }^{7}$ recommend lower target INR (1.6-2.6) for elderly patients ( $\geq 70$ years) with NVAF. Therefore, the present results cannot be extrapolated to Japanese patients with NVAF who are aged $<70$ years or to patients with NVAF of other countries where different target INR values are recommended..$^{\mathbf{5}, \mathbf{6}}$

\section{Conclusions}

Among the elderly Japanese patients with NVAF in the present study, patients belonging to the TTR $<40 \%$ group had a higher incidence of major hemorrhage than those in the no-warfarin group. In contrast, TTR $\geq 60 \%$ (or $\geq 66 \%$ ) was associated with a good prognosis with regard to thromboembolism and all-cause death.

\section{Acknowledgments}

A list of the cardiologists participating in the J-RHYTHM Registry is available elsewhere. ${ }^{16,17}$ The J-RHYTHM Registry was supported by a grant from the Japan Heart Foundation (No. 12080025), Tokyo, Japan.

\section{Conflict of Interest}

H.I. reports receiving remuneration from Daiichi-Sankyo, Bayer Healthcare, Bristol-Myers Squibb, and Boehringer Ingelheim. E.K. has received remuneration from Bristol-Myers Squibb. K.O. has received remuneration from Boehringer Ingelheim, Bayer Healthcare, and Daiichi-Sankyo. T.Y. has received research funding from Bayer Healthcare, Bristol-Myers Squibb, and Daiichi-Sankyo, as well as remuneration from Boehringer Ingelheim, Daiichi-Sankyo, Bayer Healthcare, Pfizer, Bristol-Myers Squibb, and Eisai. Y.O. has received remuneration from Bristol-Myers Squibb and Pfizer. H.O. has helped collect data for trials sponsored by Daiichi-Sankyo. H.A. has received remuneration from Daiichi-Sankyo.

\section{References}

1. Camm AJ, Accetta G, Ambrosio G, Atar D, Bassand JP, Berge E, et al. Evolving antithrombotic treatment patterns for patients with newly diagnosed atrial fibrillation. Heart 2017; 103: 307314.

2. Kodani E, Atarashi H, Inoue H, Okumura K, Yamashita T, Origasa $\mathrm{H}$. Beneficial effect of non-vitamin $\mathrm{K}$ antagonist oral anticoagulants in patients with nonvalvular atrial fibrillation: Results of the J-RHYTHM Registry 2. Circ J 2016; 80: 843-851.

3. Yamashita Y, Uozumi R, Hamatani Y, Esato M, Chun YH, Tsuji $\mathrm{H}$, et al. Current status and outcomes of direct oral anticoagulant use in real-world atrial fibrillation patients: Fushimi AF Registry. Circ J 2017; 81: 1278-1285.

4. Lip GY, Laroche C, Ioachim PM, Rasmussen LH, Vitali-Serdoz L, Petrescu L, et al. Prognosis and treatment of atrial fibrillation patients by European cardiologists: One year follow-up of the EURO observational Research Programme-Atrial Fibrillation General Registry Pilot Phase (EURO-AF Pilot registry). Eur Heart J 2014; 35: 3365-3376.

5. Kirchhof P, Benussi S, Kotecha D, Ahlesson A, Atar D, Casadei B, et al. 2016 ESC Guidelines for the management of atrial fibrillation developed in collaboration with EACTS. Eur Heart $J$
2016; 37: 2893-2962.

6. January CT, Wann LS, Alpert JS, Calkins H, Cigarroa JE, Cleveland JC Jr, et al. 2014 AHA/ACC/HRS guideline for the management of patients with atrial fibrillation: Executive summary: A report of the American College of Cardiology/American Heart Association Task Force on practice guidelines and the Heart Rhythm Society. Circulation 2014; 130: 2071-2104.

7. JCS Joint Working Group. Guidelines for pharmacotherapy of atrial fibrillation (JCS 2013): Digest version. Circ J 2014; 78: $1997-$ 2021.

8. Rosendaal FR, Cannegieter SC, van der Meer FJ, Briet E. A method to determine the optimal intensity of oral anticoagulant therapy. Thromb Haemost 1993; 69: 236-239.

9. White HD, Gruber M, Feyzi J, Kaatz S, Tse HF, Husted S, et al. Comparison of outcomes among patients randomized to warfarin therapy according to anticoagulant control: Results from SPORTIF III and V. Arch Intern Med 2007; 167: 239-245.

10. Connolly SJ, Pogue J, Eikelboom J, Flaker G, Commerford P, Franzosi MG, et al. Benefit of oral anticoagulant over antiplatelet therapy in atrial fibrillation depends on the quality of international normalized ratio control achieved by centers and countries as measured by time in therapeutic range. Circulation 2008; 118: 2029-2037.

11. Masaki N, Suzuki M, Matsumura A, Maruyama Y, Hashimoto Y. Quality of warfarin control affects the incidence of stroke in elderly patients with atrial fibrillation. Intern Med 2010; 49: $1711-1716$.

12. Haas S, ten Cate H, Accetta G, Angchaisuksiri P, Bassand JP, Camm AJ, et al. Quality of vitamin K antagonist control and 1 -year outcomes in patients with atrial fibrillation: A global perspective from the GARFIELD-AF Registry. PLoS One 2016; 11: $\mathrm{e} 0164076$.

13. Björck F, Renlund H, Lip GYH, Wester P, Svensson PJ, Själander A. Outcomes in a warfarin-treated population with atrial fibrillation. JAMA Cardiol 2016; 3: 172-180.

14. Morgan CLI, McEwan P, Tukiendorf A, Robinson PA, Clemens A, Plumb JM. Warfarin treatment in patients with atrial fibrillation: Observing outcomes associated with varying levels of INR control. Thromb Res 2009; 124: 37-41.

15. Konishi H, Miyauchi K, Kasai T, Tsuboi S, Ogita M, Naito R, et al. Adequate time in therapeutic INR range using triple antithrombotic therapy is not associated with long-term cardiovascular events and major bleeding complications after drug-eluting stent implantation. J Cardiol 2016; 68: 517-522.

16. Atarashi H, Inoue H, Oukmura K, Yamashita T, Kumagai N, Origasa $\mathrm{H}$. Present status of anticoagulation treatment in Japanese patients with atrial fibrillation: A report from the J-RHYTHM Registry. Circ J 2011; 75: 1328-1333.

17. Atarashi $\mathrm{H}$, Inoue $\mathrm{H}$, Okumura $\mathrm{K}$, Yamashita $\mathrm{T}$, Origasa $\mathrm{H}$. Investigation of optimal anticoagulation strategy for stroke prevention in Japanese patients with atrial fibrillation: The J-RHYTHM Registry study design. J Cardiol 2011; 57: 95-99.

18. Yasaka M, Minematsu K, Yamaguchi T. Optimal intensity of international normalized ratio in warfarin therapy for secondary prevention of stroke in patients with non-valvular atrial fibrillation. Int Med 2001; 40: 1183-1188.

19. Lip GY, Nieuwlaat R, Pisters R, Lane DA, Crijns HJ. Refining clinical risk stratification for predicting stroke and thromboembolism in atrial fibrillation using a novel risk factor-based approach: The Euro Heart Survey on atrial fibrillation. Chest 2010; 137: $263-272$.

20. Inoue $\mathrm{H}$, Okumura $\mathrm{K}$, Atarashi $\mathrm{H}$, Yamashita $\mathrm{T}$, Origasa $\mathrm{H}$, Kumagai N, et al. Target INR values for preventing thromboembolic and hemorrhagic events in Japanese patients with nonvalvular atrial fibrillation: Results of the J-RHYTHM Registry. Circ J 2013; 77: 2264-2270.

21. Gage BF, Waterman AD, Shannon W, Boechler M, Rich MW, Radford MJ. Validation of clinical classification schemes for predicting stroke: Results from the National Registry of Atrial Fibrillation. JAMA 2001; 285: 2864-2870.

22. Pisters R, Lane DA, Nieuwlaat R, de Vos CB, Crijns HJ, Lip GY. A novel user-friendly score (HAS-BLED) to assess 1-year risk of major bleeding in patients with atrial fibrillation: The Euro Heart Survey. Chest 2010; 138: 1093-1100.

23. Wallentin L, Yusuf S, Ezekowitz MD, Alings M, Flather M, Franzosi MG, et al. Efficacy and safety of dabigatran compared with warfarin at different levels of international normalized ratio control for stroke prevention in atrial fibrillation: An analysis of the RE-LY trial. Lancet 2010; 376: 975-983.

24. Wan Y, Heneghan C, Perera R, Roberts N, Hollowell J, Glasziou 
$\mathrm{P}$, et al. Anticoagulation control and prediction of adverse events in patients with atrial fibrillation: A systematic review. Circ Cardiovasc Qual Outcomes 2008; 1: 84-91.

25. Inoue H, Atarashi H, Okumura K, Yamashita T, Origasa H, Kumagai N, et al. Impact of gender on the prognosis of patients with nonvalvular atrial fibrillation. Am J Cardiol 2014; 113: 957 962.

26. Takabayashi K, Hamatani Y, Yamashita Y, Takagi D, Unoki T, Ishii $\mathrm{M}$, et al. Incidence of stroke or systemic embolism in paroxysmal versus sustained atrial fibrillation: The Fushimi Atrial Fibrillation Registry. Stroke 2015; 46: 3354-3361.

27. Ganesan AN, Chew DP, Hartshorne T, Selvanayagam JB, Aylward PE, Sanders P, et al. The impact of atrial fibrillation type on the risk of thromboembolism, mortality and bleeding: A systematic review and meta-analysis. Eur Heart J 2016; 37: 15911602 .

28. Inoue H, Atarashi H, Okumura K, Yamashita T, Kumagai N, Origasa H. Thromboembolic events in paroxysmal versus persistent non-valvular atrial fibrillation: Sub-analysis of the
J-RHYTHM Registry. Circ J 2014; 78: 2388-2393.

\section{Supplementary Files}

\section{Supplementary File 1}

Figure S1. Kaplan-Meier curves for the incidence of (A) thromboembolism, (B) major hemorrhage, and (C) all-cause death according to warfarin use and 2 TTR strata.

Figure S2. Kaplan-Meier curves for the incidence of the composite of thromboembolism, major hemorrhage, and all-cause death according to warfarin use and 2 TTR strata.

Table S1. Effects of TTR, time in supratherapeutic range (INR $>2.6$ ), and time in subtherapeutic range (INR <1.6) on events (univariate analysis)

Please find supplementary file(s);

http://dx.doi.org/10.1253/circj.CJ-18-0587 